
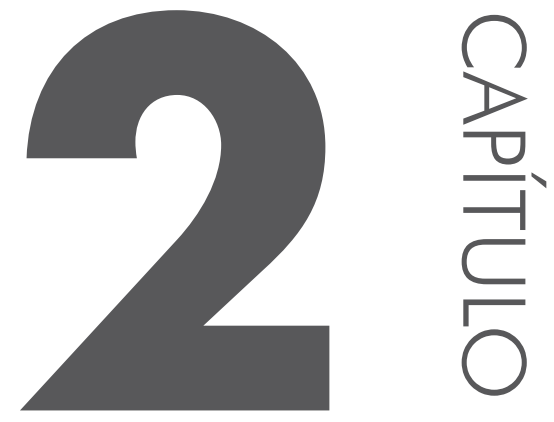

\title{
SOBRE O SIGNIFICADO IDENTITÁRIO NA SOCIOLINGUÍSTICA: A CONSTRUC̣ÃO DO GÊNERO
}

Cristine Gorski Severo

\section{INTRODUC̣ÃO}

Este capítulo pretende discutir e problematizar a dimensão social e identitária dos estudos de variação/mudança linguística com enfoque no processo de construção do gênero. Para tanto, consideraram-se os seguintes aspectos teóricos: (i) a relação entre significado social e língua, e o papel 
das avaliações sociais na (re)construção das identidades; (ii) a língua vista como prática social. Tal discussão considerará tanto textos mais clássicos da sociolinguística variacionista, como reflexões que expandem a concepção de língua para a noção de prática social. Serão considerados, também, autores que têm problematizado questões de identidade na contemporaneidade, como Hall (2006) e Brubaker e Cooper (2000). Na conclusão, são apresentadas algumas questões gerais e "precauções metodológicas" consideradas importantes para uma pesquisa que busque trabalhar na intersecção entre identidade e língua. Propõe-se que um alargamento do conceito de língua - tomada como prática social e não apenas como um sistema heterogêneo de formas linguísticas - possibilita a consideração de aspectos linguístico-discursivos fundamentais para se refletir sobre a relação língua e identidade. Dessa forma, argumenta-se a favor de um olhar mais amplo para fenômenos sociolinguísticos, em direção a uma sociolinguística crítica (SINGH, 1996; BLOMMAERT, 2012).

\subsection{LÍNGUA E SIGNIFICADOS SOCIAL E IDENTITÁRIO}

Nesta seção, explora-se a relação entre estudos variacionistas de língua e as identidades. Indaga-se, também, sobre a relação entre significado identitário e língua a partir de abordagens localmente contextualizadas.

Dentre os trabalhos emblemáticos de Labov que abordaram a dimensão identitária local da variação linguística, estão as pesquisas em Martha's Vineyard (LABOV, 1972). Sucintamente, as análises linguísticas nessa ilha revelaram uma relação entre a centralização do ditongo /ay/ (como em right e nice) e a expressão de uma atitude positiva dos moradores em relação à localidade. Tal pesquisa evidenciou o papel da identificação (social e cultural) na manutenção de um traço linguístico. Em outros trabalhos, uma das estratégias metodológicas usadas por Labov para se considerar a dimensão local dos estudos dos fenômenos de variação linguística foi a consideração das redes sociais. Labov (1973) adotou essa perspectiva, por exemplo, em pesquisas quantitativas sobre o uso do inglês afro-americano, em Nova York, para mapear a rede de relacionamentos dos membros adolescentes mais ou menos centrais e/ou periféricos do bairro do Harlem.

Outro estudo sociolinguístico (POPLACK, 1977 apud LABOV, 1978) que explora a relação entre usos linguísticos locais e identidade étnica envolve a aquisição do inglês por alunos porto riquenhos na Filadélfia. A pesquisa mostrou uma apropriação linguística, por alunos (meninos) porto riquenhos, do inglês afro-americano em contextos informais de escolas da Filadélfia, e uma apropriação do inglês branco não-padrão em contextos formais pelas alunas; nota-se, neste caso, uma divisão linguística de gêne- 
ro. Além desse trabalho, pode-se exemplificar os estudos sobre variação linguística e aspectos identitários locais com a pesquisa de Eckert (2000) sobre a variação linguística como prática social. Sucintamente, a autora, a partir de uma longa experiência etnográfica em uma escola pública de Detroit, evidenciou, pela noção de comunidade de prática, a existência de dois grupos polarizados na escola - os Jocks e os Burnouts. A diferença linguística entre ambos sinalizaria para duas atitudes: enquanto os Jocks, orientados para a vida institucional, tendem a acatar as regras da escola, os Burnouts, orientados para uma vida urbana, resistem a tais regras, tentando subvertê-las; nesse caso, classe social e gênero estariam fortemente vinculados à mudança linguística em progresso. Contudo, nesse contexto, os agentes da uniformização linguística não seriam esses dois grupos, mas os chamados "in-betweens", que sobrepunham as atitudes rebeldes dos Burnouts aos usos linguísticos dos Jocks (LABOV, 2002).

Os trabalhos etnográficos de Eckert (2000, p. 228) possibilitaram a seguinte afirmação teórica pela autora: “O significado social da variação é construído pelas diferentes maneiras como os falantes individuais estão vinculados, por um lado, a seus amigos mais próximos e, por outro, ao nível mais abstrato de organização social" ${ }^{1}$. Disso depreende-se que: (i) o significado social da variação não é dado, mas construído; (ii) essa construção vincula-se, por um lado, às formas de relação dos sujeitos com seus pares e, por outro, às formas de ligação dos sujeitos a uma dimensão social mais ampla. Além desses aspectos, uma outra característica que define o significado social e estilístico de uma dada variável linguística é a sua sensibilidade à apreciação social e, portanto, ao monitoramento pelo sujeito. Tal sensibilidade atrela-se à ideia de nível de consciência social que, segundo Weinreich, Labov e Herzog (1968, p. 124), "é uma propriedade importante da mudança linguística que tem que ser determinada diretamente”. $\mathrm{O}$ papel do significado social da variável linguística foi ratificada por Labov (1972, p. 23), ao afirmar que "apenas quando o significado social é vinculado a tais variações que elas serão imitadas e começarão a desempenhar um papel na língua." 2

A construção linguística de identidades não pode ser vista a partir de elementos linguísticos isolados e quantificados. Há um conjunto de traços linguísticos, juntamente com outros elementos semióticos, que atuam na construção de uma dada identidade (SEVERO; NUNES, 2015): É o caso,

1 "The social meaning of variation is built into the very means by which individual speakers are connected to their closest friends on the one hand, and the most abstract level of social organization on the other." As traduções são de responsabilidade das autora.

2 "Only when social meaning is assigned to such variations will they be imitated and begin to play a role in the language." 
por exemplo, do manezinho da ilha de Florianópolis cuja identidade é reconhecida, entre outros aspectos, pelo uso de certos elementos linguísticos, como: prosódia acelerada, uso de uma variante não africada diante da realização da oclusiva dental diante de [i] (como em tia e dia), uso de marcadores discursivos "não tem" e "entendesse", uso do pronome tu, além de altos índices de monotongação, entre outros aspectos (SEVERO; NUNES, 2015; VALLE, 2014).

Além de um conjunto de fenômenos linguísticos, a construção de uma dada identidade não depende apenas da vontade consciente dos sujeitos. Isso porque as identidades não podem ser vistas como categorias estáveis e estanques autorreguladas, mas como processos que se dão a partir de três aspectos interligados (BRUBAKER; COOPER, 2000):

- Processo de auto-identificação: Como alguém se identifica com uma dada categoria identitária? Por exemplo, ser mulher ou nativa da ilha de Santa Catarina?

- Processo de identificação pelo outro: Como as pessoas identificam alguém de uma dada maneira?

- Processo de identificação institucional: Como os discursos oficiais identificam/categorizam uma dada identidade?

Esses três elementos tornam mais complexa a relação entre usos linguísticos e questões identitárias. Diante disso, por exemplo, os traços linguísticos que assumem significados sociais e identitários deveriam ser "validados" não apenas pelos próprios sujeitos, mas também por outros sujeitos e pelas instituições. Nessa perspectiva, as reflexões que buscam vincular usos linguísticos a aspectos identitários - língua das mulheres, das manezinhas (nativas de Florianópolis), das rendeiras, das juízas, etc. - deve considerar a importância de um levantamento das apreciações sociais sobre os usos linguísticos feitos pelas pessoas. A partir disso, propõe-se que os "testes de atitude" podem ser instrumentos metodológicos interessantes para se considerar as apreciações sociais sobre os usos linguísticos associados a aspectos identitários. Tais testes de atitude podem incluir uma gama de instrumentos que captem a apreciação social. Como exemplos de testes de atitude "informais", podem-se considerar postagens em redes sociais que usam a língua como bandeira identitária, mesmo que seja para fins de estilização paródica (BAKHTIN 1952-1953), conforme ilustra-se na figura 1. 
Figura 1: Recortes da página do Facebook, com 3.300 curtidas

(Março, 2014).

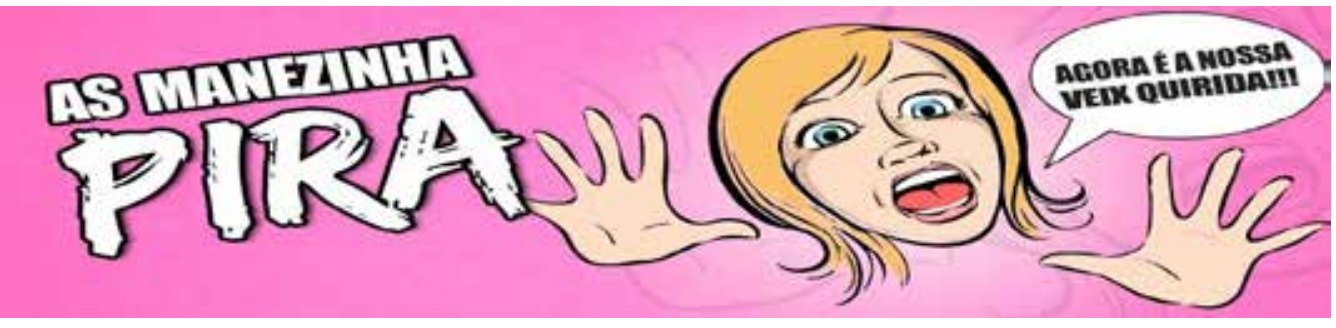

TÔ FIFALANDO PRA TI

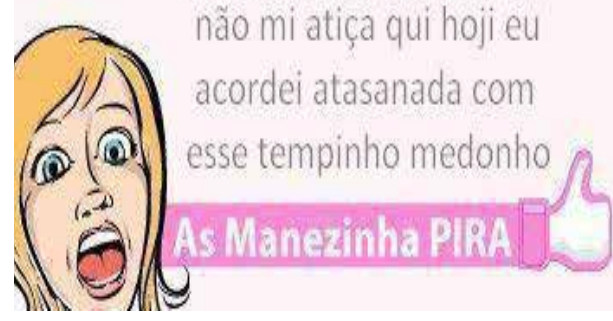

HOJE NÃO TEM JANTA QUIRIDU

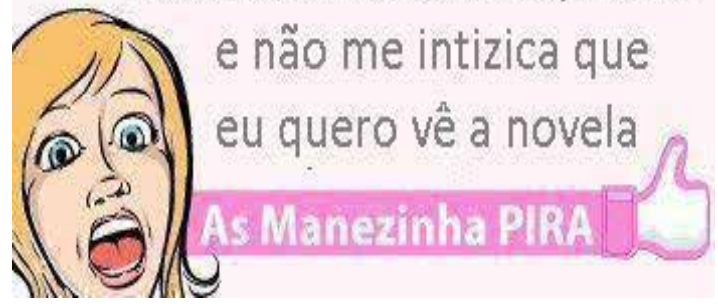

A construção linguístico-discursiva de “personas” ratifica certos significados sociais e estilísticos atribuídos à língua como, por exemplo, as ideias de beleza, inteligência, competência e desenvoltura em relação às formas de expressão dos sujeitos. Os níveis de apreciação social dos usos linguísticos têm sido definidos, pela sociolinguística variacionista, em relação a três categorias que atuam num contínuo valorativo: os estereótipos, com maior força avaliativa e sensível à discussão metapragmática, os marcadores, com força avaliativa mediana, e os indicadores, que indexam significados regionais e não são sensíveis ao eixo formalidade-informalidade (ECKERT, 2008; LABOV, 1971). Além disso, os estereótipos são, em alguns casos, usados para ratificar tipos sociais, como é o caso da "mulher histérica" (acordei atazanada) ou da mulher dona-de-casa, que cozinha para seu marido ou que assiste novelas. Outro exemplo de identificação de aspectos identitários a partir da avaliação linguística pode ser conferido pelo depoimento de uma das entrevistadas do Banco da Amostra Floripa (VARSUL, 2014), abaixo:

(1)

E [entrevistadora]: O que é ser manezinho pra você?

I [informante]: Ah, eu não percebo no meu falar, mas assim, vocês já foram na Costa da Lagoa?

E: Eu só fui pra ir no restaurante. 
I: O pessoal lá tem o sotaque muito forte. Aqui em Ratones tem pessoas que não tem o sotaque tão forte, mais as gírias e o jeito de falar. (A., 32, F.)

Muitos outros exemplos sobre atribuições de valorações aos sujeitos a partir do seu comportamento linguístico são encontrados na mídia, como valorações condenatórias sobre a variedade falada por Lula ou a atribuição de valores "masculinos" ao jeito de falar de Dilma Rousseff, conforme ilustra o seguinte excerto publicado no jornal Brasil Post $(02 / 05 / 2015)^{3}$ :

'É aquela pessoa que bate na mesa, que fala que eu vou fazer $e$ acontecer, eu sei. Isso é, no estereótipo, uma liderança muito mais patriarcal, do coronelismo brasileiro'. Assim a coordenadora do programa de governo de Marina Silva, Maria Alice Setubal, definiu a presidente e candidata à reeleição Dilma Rousseff, em entrevista à Folha e ao portal UOL.

O patriarcalismo define uma sociedade de dominação masculina. No caso do comentário acima, o uso de construções categóricas, incisivas e em primeira pessoa feito pela presidenta Dilma seria visto por Maria Alice como traço de masculinidade. Tal visão reducionista e estereotipada ratifica algumas conclusões levantadas em pesquisas sociolinguísticas de gênero do início dos anos 1970 (LAKOFF, 2010[1972]). É curioso averiguar como essas observações registradas por Lakoff - frutos de um trabalho ainda incipiente sobre a questão de gênero - ecoam em apreciações feitas por mulheres em relação a outras mulheres que ocupam lugares de liderança política. Outros exemplos incluem programas humorísticos, telenovelas e filmes que constroem tipos sociais atrelados a certos comportamentos linguísticos, reforçando estereótipos sociais a partir da língua.

Diante do exposto, é pertinente levar em conta que a construção da relação entre identidade e língua deve considerar, além da dimensão local de anexação dos significados identitários, as formas de circulação social e midiática desses significados, bem como as diferentes formas como tais significados são interpretados e ressignificados pelos sujeitos. Isso implica que valores pejorativos, depreciativos ou positivos variam. Por exemplo, o uso daqueles traços linguísticos mencionados anteriormente como característicos do "manezês" foram, historicamente, alvo de deboche e de depreciação identitária, conforme os excertos abaixo ilustram:

(2)

[...] se tu vai pro interior do Ribeirão da Ilha, onde lá, onde lá não chegou, lá tu vai encontrá o manezinho típico, que pouca influência tem desse mundo que taí [...] (VARSUL - 40, F.)

3 Disponível em <http://www.brasilpost.com.br/2014/08/22/dilma-masculina_n_5699118.html> 
(3)

[...] meu linguajar não traz aquele traço da nossa cultura, do nosso linguajar cantado [...] aquele que fala oi, oi , o coitado, aquele né (VARSUL - 40, F.)

E: A senhora acha bonito o jeito de vocês falarem aqui?

I: É, porque sou manezinha.

E: E o que que é ser manezinha?

I: Porque não sabe nada, eu acho, né. Não fala bem, não sabe pronunciar, não sabe como é que se diz as palavra, né? Agora, não sei porque criou esse nome de manezinho, né, não sei. (VARSUL, Amostra Floripa - 50, F. $)^{4}$

Tais traços linguísticos têm sido ressignificados diante de uma revalorização da identidade do manezinho nos últimos anos (AMANTE, 1998), como fruto de iniciativas institucionais, de "mercantilização" da tradição e de resistência aos estrangeiros em defesa de uma forma de vida local.

Diante do exposto, propõe-se que a articulação entre língua e identidade (de gênero, por exemplo) leve em conta a complexidade que envolve a indexação de significados identitários aos usos linguísticos, a forma de circulação desses usos e significados, e as formas de recepção desses significados. Esquematicamente, propõe-se o seguinte modelo que interliga a produção, circulação e recepção dos significados identitários indexados à língua (Figura 2).

4 As informações no final da transcrição sinalizam para os dados das informantes: o número representa idade e a letra $\mathrm{F}$ representa o sexo. 


\section{Figura 2: Percurso geral dos significados linguístico-identitários}

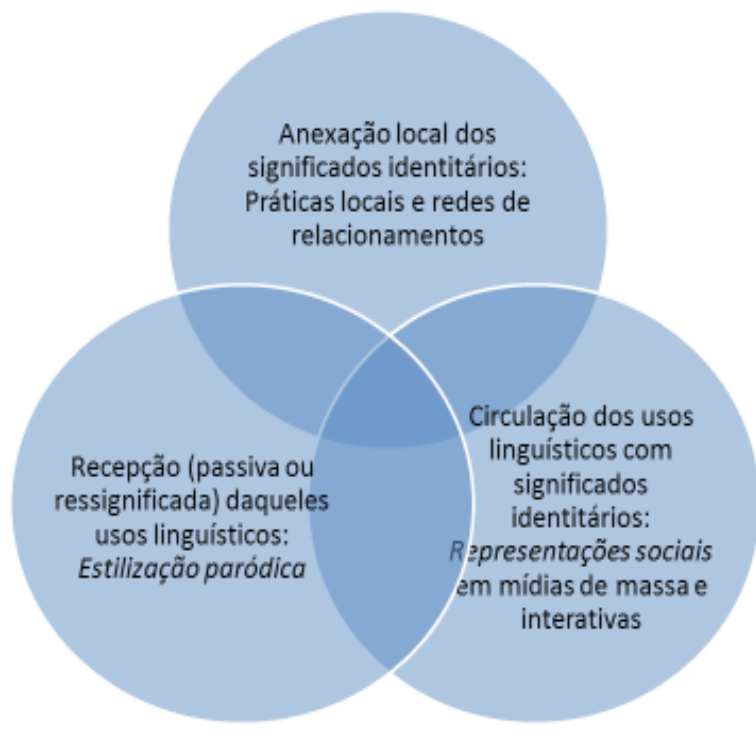

Finalizando, nesta seção foi feita uma breve apresentação de pesquisas sociolinguísticas de cunho variacionista sobre a relação entre língua e identidade, a partir de um olhar sobre a identidade local. O conceito de identidade foi problematizado a partir de um olhar mais amplo e dialógico, que integre a relação dos sujeitos consigo, com os outros e com as instituições. Além disso, foram feitas aproximações entre a apreciação social dos usos linguísticos e os significados identitários. Uma série de exemplos ilustraram estereótipos que ratificam certas visões sobre língua e identidade feminina. Por fim, essa seção propôs, de forma esquemática, um pequeno modelo que considere - nas pesquisas sobre a relação entre usos linguísticos e aspectos identitários - a interrelação entre as instâncias de produção, circulação e recepção dos significados sociais. A seguir, aborda-se a língua a partir de um olhar mais amplo, que considere as práticas sociais.

\subsection{A LÍNGUA COMO PRÁTICA SOCIAL: AMPLIANDO OS HORIZONTES LINGUÍSTICOS}

A construção da relação entre identidade de gênero e língua extrapola a dimensão propriamente linguística (fonológica, prosódica, morfossintática, lexical e textual), incluindo práticas linguísticas mais amplas, como é o caso, por exemplo, das cantigas e das rezas (orações) praticadas pelas 
rendeiras de Florianópolis. Nas práticas sociais, considera-se que os sujeitos não usam os significados sociais e estilísticos, mas os produzem e reproduzem (ECKERT, 2008). No contexto das práticas sociais, uma série de recursos semióticos são integrados para a produção de sentidos. Assim, as identidades são vistas como produtos e produtoras das práticas sociais. E os usos linguísticos emergem contextualizados a essas práticas. Além disso, considerando que as práticas sociais não são estáticas, os significados sociais e estilísticos também não o são, conforme vimos na seção anterior sobre a ressignificação dos significados identitários do manezinho da ilha de Santa Catarina.

A dimensão mutante dos significados identitários - como no caso de uma revalorização da "tradição" - é afirmada por Hall (2006) a partir dos efeitos que a globalização e migrações estariam produzindo sobre as identidades: (i) as identidades estariam em uma espécie de crise, o que favoreceria processos de fragmentação e desterritorialização das identidades; (ii) tal fragmentação teria motivado movimentos de resistência em direção a um reforço ou reformulação das identidades locais, o que se evidencia pela busca de memórias, pelo compartilhamento de aspectos comuns e pela perpetuação da herança; (iii) os deslocamentos e encontros entre culturas teria promovido a emergência de novas identidades híbridas. No contexto de Florianópolis, percebe-se um movimento de revalorização da identidade das mulheres mais idosas da ilha pelo interesse midiático de entrevistá-las, pelo investimento da Secretaria de Cultura de Florianópolis nas práticas "tradicionais", pela quantidade de pesquisas acadêmicas sobre essas mulheres e suas práticas e pela mercantilização de suas rendas (e saberes tradicionais) como artesanato local.

Considerando que as identidades não operam de forma unitária, mas de maneira intersectada, explorar as práticas linguísticas das rendeiras de Florianópolis implica considerar lugares de intersecção de identidades de gênero (feminino) e de tradição. Ao se levar em conta uma dimensão complexa de identidade e de línguas vinculada às práticas sociais, propõe-se, metodologicamente, um estudo que considere uma interligação entre três aspectos, considerados a seguir:

(i) Formas de nomeação, designação, representação imagética e valoração dessas identidades. No caso das rendeiras, suas práticas foram ressignificadas historicamente, sendo que essa valorização favoreceu o alçamento dessas mulheres ao espaço público, ao papel de contadoras de história, de empresárias, de detentoras de um saber tradicional e de mestras e educadoras na arte da renda. Alguns nomes próprios tornaram-se símbolos dessa mulher: Dona Teodora, a "grande manezinha", de Jurerê; Dona Aldazira, do Rio Tavares; Dona Delícia e Tia Ilda, benzedeiras do Pântano do Sul. 
Além de rendeiras, as mulheres de Florianópolis são significadas em relação a uma memória associada às bruxas, curandeiras, benzedeiras ou parteiras. Os excertos abaixo, oriundos da Amostra Floripa (VARSUL, 2014), ilustram essas representações como um lugar de singularização da mulher.

E: A tua mãe fazia renda de bilro?

I: Renda de bilro.

E: Pra ela ou pra vender?

I: Ela conta que na infância dela ela fazia porque perdeu o pai dela muito cedo. (VARSUL, 32, F.)

(6)

E: E história de bruxa?

I: É, eles comentavam, mas nunca vi nem quero ver. Diz que tinha, não sei. As crianças chorava, ficava meio inchadinha, 'ai ó, foi a bruxa que te embruxou'.

E: E tinha alguém por aqui que falavam que era bruxa?

I: Ah, diziam, fulana de tal é bruxa.

E: Por que?

I: Fazia trança em crina de cavalo, não sei.

E: Mas olhando pra pessoa? Por que diziam 'ai, aquela ali é bruxa?' I: "É eles achavam elas assim diferente, não sei, eu nunca achei. (VARSUL, 50, F.)

E: A senhora já levou algum dos seus filhos em alguma benzedeira? I: Uhum. A mais velha. Benzer de susto. Que ela sempre levava susto. Daí eu pensei: 'tá assustada por quê, né?' Essa benzedeira benzia só de susto. (VARSUL, 50, F.)

(ii) Essas formas de designação não são isoladas, mas se alinham a práticas sociais e linguísticas específicas: benzedura, cantigas de roda, orações, contação de histórias de bruxa, feitura de rendas de bilros, boi-de-mamão, ratoeira (dança de roda embalada por versos), partos e cozinha (farinha, tainha). Sobre a cantiga de ratoeira, mais especificamente, trata-se de uma dança em que as mulheres cantavam uma cantiga com temas voltados para o universo amoroso e de encantamento dos rapazes. Abaixo ilustra-se o trecho de duas ratoeiras (PEREIRA et al., 1990): 
Vou fazer a minha cama

$\mathrm{Na}$ virada para o rio

Para ver o meu amor

Quando passar no navio.

O sol é caixão de prata

A lua é a fechadura

As estrelas são as chaves

Que fechava nossa ventura.
Minha mãe quer me casar prometeu tudo que tinha depois de me ver casada deu três sacos de farinha

Se tu soubesses cantar como eu sei de cantiga fazia as velhas rir quanto mais as rapariga

Trata-se de cantigas que seguem uma estrutura composicional na forma de rimas e de diálogos, com uma puxadora orientando as trovas e trocas de turno, com temáticas voltadas para as relações afetivas de casamento e de amizade. A historicização dessas cantigas as remete ao trovadorismo português, com as cantigas de amor e de amigo que eram entoadas, tipicamente, por um eu-lírico masculino (LIMA, 2013). No caso das mulheres da ilha, trata-se de um eu-lírico feminino que emerge a partir de um complexo semiótico que envolve dança, canto, letra e uso de roupas específicas (saias, pulseiras, lenços e blusas bordadas). Nesse sentido, a língua (prosódia, pronúncia, morfossintaxe, léxico) surge como produto desse complexo semiótico em que as mulheres constituem-se enquanto cantam, dançam e produzem sentidos.

(iii) Além das formas de designação e das práticas linguísticas, um outro lugar de construção linguístico-discursiva de identidade são as narrativas de mulheres que advogam ter forte vínculo afetivo com a Ilha. Tais narrativas - muitas das quais foram depreendidas de entrevistas realizadas para a construção da Amostra Floripa pelo Núcleo VARSUL (2014) - incluem temas variados que se vinculam ao universo vivido por essas mulheres. Além da Amostra Floripa, há uma série de documentários ${ }^{5}$ sobre as rendeiras de Florianópolis com vistas a uma valorização da tradição local. Nesses documentários são ilustrados temas variados associados ao imaginário que intersecta tradição e identidade (feminina): rendas, rede, tarrafa, cantigas da ratoeira, bruxas, benzeduras, comidas (farinha, pirão), partos, lavação de roupas, festas (Divino Espírito Santo), relação entre passado e presente. No caso das rendas, o bilro é visto como uma arte passada informalmente entre gerações, como um saber tradicional familiar que requer "paciência e técnica”. Em alguns desses documentários, as mulheres ensinam a fazer

5 Alguns exemplos podem ser encontrados nos seguintes sítios: sobre a renda de bilro: https:// www.youtube.com/watch?v=qBckHtDLKgo e http://www.youtube.com/watch?v=ienO8aI267Y; sobre memórias da infância: http://www.youtube.com/watch?v=u0F7epsUugg; sobre as cantigas e o bilro: http://www.youtube.com/watch?v=ZLBEKHr31Ns. 
renda e, nesse contexto, a língua emerge como um lugar de visibilização das mulheres, de sua voz e conhecimento. Tal fato fica evidenciado pela criação de associações, que formalizam a técnica e mercantilizam a prática e os produtos, lugares onde essas mulheres assumem um protagonismo econômico também em relação a sua família.

O protagonismo assumido pelas mulheres rendeiras - pela apropriação e discursivização da prática de fazer renda tomada como um saber tradicional - é também ratificado pela construção do blog rendeirasdebilro, que publica uma série de vídeos e depoimentos sobre a "mulher rendeira”. Nesse contexto, trata-se de considerar a visibilização dos discursos e das mulheres rendeiras como um lugar de ressignificação dos papéis sociais, políticos e culturais das mulheres a partir da relação consigo mesmas (e com suas memórias), da relação com os outros (que as identificam como "mestras" da arte de fazer renda) e da relação com as instituições (como a prefeitura e as associações culturais), que legitimam sua prática e seus saberes. As práticas linguísticas - na forma de narrativas, cantigas, diálogos, piadas, brincadeiras, provérbios, rezas, etc. - emergem como produto desses processos identitários em que o que está em jogo é o direito de falar e de ter sua voz validada e reconhecida. Trata-se de práticas linguísticas tomadas como práticas sociais.

Adaptando ao estudo das práticas sociais das mulheres da ilha o modelo proposto na seção 2.2 para o estudo da relação entre identidade e significados identitários, tem-se a proposta metodológica da figura 3. 
Figura 3: Percurso especifico dos significados linguístico-identitários

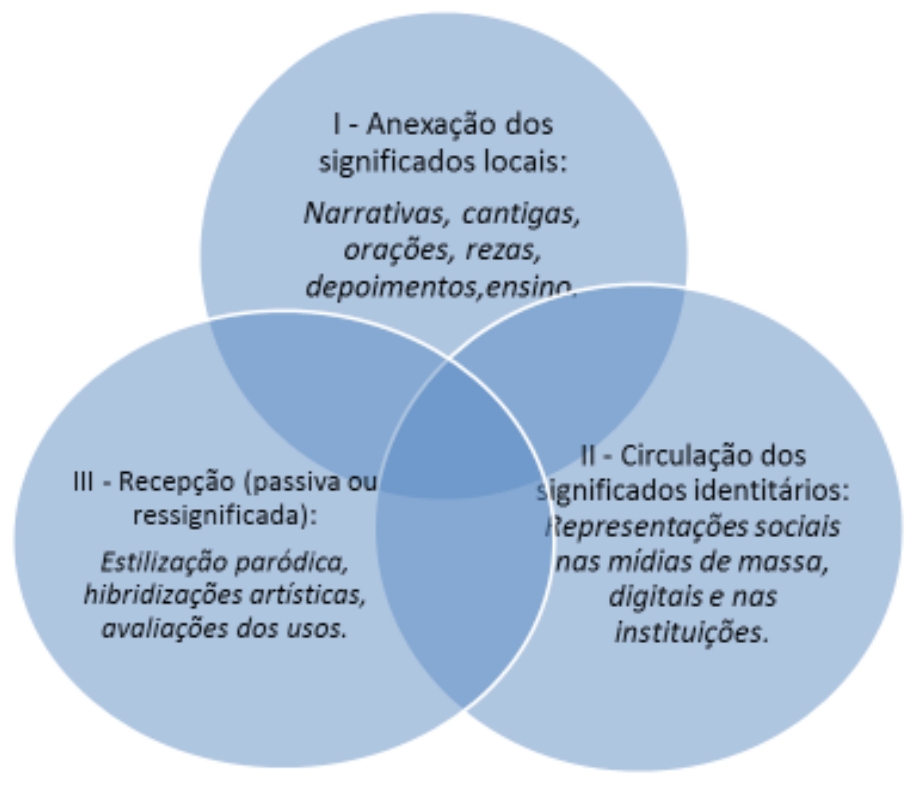

Finalizando, esta seção teve como foco explorar a concepção de língua como prática social. Nesse caso, trata-se de considerar que a língua se integra a um complexo semiótico mais amplo, que envolve cantos, danças, vestimentas, rezas, entre outros. É na prática social que as mulheres constituem-se, na relação consigo, com outros e com as instituições. Além disso, se defende uma visão de identidade de gênero interligada à tradição, pois se considera que as identidades são múltiplas e, portanto, correlacionam-se continuamente.

\section{PALAVRAS FINAIS}

As reflexões em torno das mulheres e dos significados identitários que se inscrevem em suas línguas e práticas linguísticas levantam questões como foco para futuras reflexões:

- De que maneira os sujeitos constroem discursiva e linguisticamente a sua identidade local?

- De que maneira a tradição é (re)construída e linguística e discursivamente?

- Em que medida os sujeitos ao identificarem os significados sociais e identitários das variantes utilizam-nas como índices na construção 
de uma identidade local?

- De que maneira os deslocamentos dos sujeitos favorecem a emergência de categorias linguístico-discursivas híbridas em termos de significado social identitário?

- Como significados identitários locais são construídos, mantidos e propagados?

Em diálogo com tais questões, assumimos como "precauções teórico-metodológicas”, algumas reflexões que incluem a consideração dos seguintes aspectos:

(i) Os usos linguísticos assumem significado social de tradição em práticas linguísticas locais e passam a ser assimilados, ressignificados e propagados pelas interações locais, pelas mídias, pelas instituições.

(ii) A estabilização de significados de identidades de tradição envolve fatores discursivos, como a valorização da identidade regional como um bem simbólico, cultural e econômico - Ser manezinho passa a ser marca de prestígio cultural.

(iii) Os sujeitos avaliam os usos linguísticos e essa avaliação afeta a escolha/uso de uma variante ou outra com finalidade de construção de uma dada identidade.

(iv) As avaliações dos usos linguísticos com marcas identitárias não são estanques e homogêneas, mas podem ser sistematizadas em uma escala avaliativa e relativamente variável.

(v) A gradação avaliativa produz efeitos sobre os usos das variantes.

(vi) É possível - e necessário - apreender as avaliações dos sujeitos sobre usos linguísticos. 


\section{REFERÊNCIAS}

AMANTE, Francisco Hegídio. Somos todos manezinhos. Florianopolis: Papa-Livro, 1998.

BAKHTIN, Mikhail. O discurso no romance (1934-35). In: Questões de Literatura e de Estética: a teoria do romance. São Paulo: Unesp, 1998 [1988].

BLOMMAERT, Jan. Supervernaculars and their dialects. Dutch Journal of Applied Linguistics, v. 1, n. 1, 2012. p. 1-14.

BRUBAKER, Roger; COOPER, Frederic. Beyond 'Identity'. Theory and Society, 29, p. 1-47, 2000.

ECKERT, Penelope. Linguistic variation as social practice. Oxford: Blackwell, 2000.

ECKERT, Penelope. Variation and the indexical field. Journal of Sociolinguistics 12/4, p. 453-476, 2008.

HALL, S. A identidade cultural na pós-modernidade. Trad. Tomaz Tadeu da Silva; Guaracira Lopes Louro. 11. ed. Rio de Janeiro: DP\&A, 2006.

LABOV, William. The study of language in its social context. In: Fishman, J. A. (org.) Advances in the Sociology of Language, vol. 1. The Hague/The Netherlands: Mouton, 1971, p.152-216.

LABOV, William. Sociolinguistic Patterns. Pennsylvania: University of Pennsylvania Press, 1972.

LABOV, William. The linguistic consequences of being a lame. Language in Society, 2, p. 81-115, 1973.

LABOV, William. Crossing the Gulf between Sociology and Linguistics. The American Sociologist, v. 13, n. 2, p. 93-103, 1978.

LABOV, William. Review of Penelope Eckert, Linguistic variation as social practice. Language in Society, n. 31, p. 277-306, 2002.

LAKOFF, Robin. Linguagem e lugar da mulher (1973). In: OSTERMANN, C.; FONTANA, B. (orgs). Linguagem, Gênero Sexualidade. São Paulo: Parábola, 2010. p.13-30.

LIMA, Sumaya Machado. Ratoeira bem cantada e cantigas de amigo: possíveis diálogos que atravessaram o tempo. Seminário Internacional Fazendo Gênero 10 (Anais Eletrônicos). Florianópolis, 2013.

PEREIRA, Nereu do Vale; PEREIRA, Francisco do Vale; NETO, Waldemar Joaquim da Silva. Ribeirão da Ilha, vida e retratos - um distrito em destaque. Florianópolis: Fundação Franklin Cascaes, Coleção Memória de Florianópolis, n. 3, 1990.

POPLACK, Shana. On dialect acquisition and communicative competence: the 
case of Puerto Rican Bilinguals. Language in Society 7, 1978. p. 89-104.

SEVERO, C. G.; SOUZA, C. M. N. identidade e língua na ilha de Santa Catarina: sobre a relação entre o manezinho e o manezês. In: SAVEDRA, M. M. G; MARTINS, M. A.; DA HORA, D. (orgs.). Identidade social e contato linguístico no português brasileiro. Rio de Janeiro: EdUERJ, 2015, p.13-36.

SINGH, Rajendra. Towards a Critical Sociolinguistics. Amsterdam: John Benjamins, 1996.

VALLE, Carla Regina Martins. Multifuncionalidade, mudança e variação de marcadores discursivos derivados de verbos cognitivos: forças semântico-pragmáticas, estilísticas e identitárias em competição. Tese de Doutorado do Programa de Pós-Graduação em Linguística. Florianópolis: UFSC, 2014. 